\title{
ОСОБЕННОСТИ ЛИПИДОМА У БОЛЬНЫХ С РАЗЛИЧНОЙ КЛИНИЧЕСКОЙ ВЕРОЯТНОСТЬЮ СЕМЕЙНОЙ ГИПЕРЛИПИДЕМИИ
}

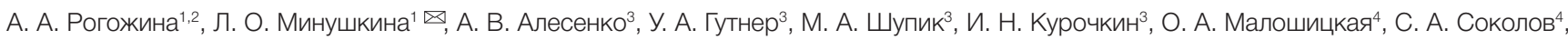
Д. А. Затейщиков ${ }^{1,2}$

${ }^{1}$ Центральная государственная медицинская академия Управления делами Президента Российской Федерации, Москва, Россия

2 Городская клиническая больница № 51, Москва, Россия

${ }^{3}$ Институт биохимической физики имени Н. М. Эмануэля РАН, Москва, Россия

${ }^{4}$ Московский государственный университет имени М. В. Ломоносова, Москва, Россия

\begin{abstract}
Разработка современных методов оценки метаболома, таких как хромато-масс-спектрометрия, позволяет существенно расширить представления о липидном обмене в конкретных клинических ситуациях. Целью исследования было изучить особенности липидома у больных с различной вероятностью семейной гиперхолестеринемии (СГХС). В исследовании приняли участие 35 пациентов - 15 мужчин (42,9\%) и 20 женщин (57,1\%) с дислипидемией или ранними сердечно-сосудистыми заболеваниями, развившимися в возрасте до 55 лет у мужчин и до 60 лет у женщин. Средний возраст пациентов составил 49,8 \pm 9,96 лет. Вероятность семейной дислипидемии оценивали по критериям сети голландских липидных клиник. У 10 пациентов вероятность СГХС оценивали как низкую (1-2 балла), у 22 пациентов диагноз расценивали как вероятную СГХС (3-5 баллов). У 3 пациентов присутствовала возможная или определенная СГХС (2 пациента - 6 баллов, один пациент - 9 баллов). Определение молекулярных видов сфингомиелинов, церамидов и сфингоидных оснований (сфингозина, сфинганина), а также галактозоцерамида проводили методом хроматомасс-спектрометрии. Пациенты с определенной/вероятной СГХС имели достоверно более высокий уровень сфингозина по сравнению с пациентами с низкой клинической вероятностью СГХС (144,36 \pm 107,863 и 50,14 \pm 62,409 нг/мл; p = 0,01). В случае семейной СГХС отмечали увеличение доли длинноцепочечного сфингомиелина SM $18: 1 / 22: 0$ и существенное увеличение уровня церамидов с длинной углеродной цепью С $20: 1$ и С $22: 1$. Была выявлена значимая прямая корреляция уровня липопротеинов низкой плотности (ЛНП) и сфингозина ( $r=0,344 ; p=0,047)$ наряду с обратными корреляциями уровня липопротеинов высокой плотности (ЛВП), сфинганина $(r=-0,52 ; p=0,002)$ и галактозилцерамида $(r=-0,56 ; p=0,001)$. Таким образом, у пациентов с высокой клинической вероятностью СГХС были выявлены изменения липидома, являющиеся маркерами риска сердечнососудистых осложнений.
\end{abstract}

Ключевые слова: атеросклероз, семейная гиперлипидемия, сфингомиелины, сфингозин, церамиды, маркеры риска

Финансирование: грант РФФИ 19-04-00870А «Сфинголипидомный анализ маркеров сердечно-сосудистых заболеваний».

Информация о вкладе авторов: А. А. Рогожина - отбор материала, сбор данных; Л. О. Минушкина - анализ полученных данных, написание статьи; Д. А. Затейщиков - планирование работы, анализ данных, подготовка публикации; А. В. Алесенко - руководитель проекта; У. А. Гутнер, М. А. Шупик, О. А. Малошицкая и С. А. Соколов - пробоподготовка, проведение лабораторных исследований, анализ данных; И. Н. Курочкин - анализ данных.

Соблюдение этических стандартов: исследование одобрено этическим комитетом ГБУЗ «Городская клиническая больница № 51 ДЗМ» (протокол № 02/19 от 7 февраля 2019 г.). Все пациенты подписали добровольное информированное согласие на участие в исследовании.

$\varangle$ Для корреспонденции: Минушкина Лариса Олеговна Филевский б-р, 36-19, г. Москва, 121601; minushkina@mail.ru

Статья получена: 30.11.2019 Статья принята к печати: 18.12.2019 Опубликована онлайн: 26.12.2019

DOI: $10.24075 /$ vrgmu.2019.090

\section{LIPIDOME FEATURES IN PATIENTS WITH DIFFERENT PROBABILITY OF FAMILY HYPERCHOLESTEROLEMIA}

Rogozhina $\mathrm{AA}^{1,2}$, Minushkina LO ${ }^{1} \otimes$, Alessenko AV ${ }^{3}$, Gutner $\mathrm{UA}^{3}$, Shupik MA³ , Kurochkin $\mathrm{IN}^{3}$, Maloshitskaya OA${ }^{4}$, Sokolov SA ${ }^{4}$, Zateyshchikov DA ${ }^{1,2}$

${ }^{1}$ Central State Medical Academy under the Administrative Department of the President of the Russian Federation, Moscow, Russia

${ }^{2}$ City Clinical Hospital № 51, Moscow, Russia

${ }^{3}$ Institute for Biochemical Physics, Moscow, Russia

${ }^{4}$ Lomonosov Moscow State University, Moscow, Russia

Development of modern methods for metabolome assessment, such as gas chromatography-mass spectrometry, allows one to expand the knowledge about the features of lipid metabolism in various clinical conditions. The study was aimed to investigate lipidome features in patients with different probability of family hypercholesterolemia (FH). The study involved 35 patients: 15 men (42.9\%) and 20 women (57.1\%) with dislipidemia or early cardiovascular diseases which manifested below 55 in men and 60 in women (average age of patients was $49.8 \pm 9.96$ ). The family dislipidemia probability was evaluated using the Dutch Lipid Clinic Network Score. In 10 patients the probability of FH was low (score 1-2), 22 patients had possible FH (score 3-5). Three patients had probable or definite FH (score 6 in 2 patients, score 9 in one patient). Determination of molecular species of sphingomyelins, ceramides and sphingoid bases (sphingosine, sphinganine) as well as galactosylceramide was carried out using gas chromatography-mass spectrometry. In patients with definite/probable FH the sphingosine level was significantly higher compared with patients having low probability of $\mathrm{FH}(144.36 \pm 107.863$ and $50.14 \pm 62.409 \mathrm{ng} / \mathrm{ml} ; p=0.01)$. In patients with $\mathrm{FH}$, an increase in the proportion of long chain sphingomyelin SM $18: 1 / 22: 0$ as well as a significant increase in the level of long chain ceramides with $C 20: 1$ and $C 22: 1$ was determined. Positive correlation of low-density lipoproteins and sphingosine level $(r=0.344 ; p=0.047)$ together with negative correlation of high-density lipoproteins (HDL), sphinganine $(r=-0.52 ; p=0.002)$, and galactosylceramide level $(r=-0.56 ; p=0.001)$ were detected. Thus, in patients with high probability of $\mathrm{FH}$ the lipidome changes were observed, which could be considered the cardiovascular risk markers.

Keywords: atherosclerosis, family hyperlipidemia, sphingomyelins, sphingosine, ceramides, risk marker

Funding: RFBR grant 19-04-00870A Sphingolipidome Analysis of Cardiovascular Diseases' Markers.

Author contribution: Rogozhina AA — sampling, data acquisition; Minushkina LO — data analysis, text writing; Zateyshchikov DA — planning, data analysis, manuscript writing; Alessenko AV — project manager; Gutner UA, Shupik MA, Maloshitskaya OA and Sokolov SA — sample preparation, laboratory analysis, data analysis; Kurochkin IN - data analysis.

Compliance with ethical standards: the study was approved by the Local Ethics Committee of City Clinical Hospital № 51 (protocol № 02/19 dated February 7 , 2019). Informed consent was obtained from all study participants.

$\triangle$ Correspondence should be addressed: Larisa O. Minushkina

Filevsky Boulevard, 36-19, Moscow, 121601; minushkina@mail.ru

Received: 30.11.2019 Accepted: 18.12.2019 Published online: 26.12.2019

DOI: 10.24075/brsmu.2019.090 
Нарушения липидного обмена, в том числе наследственного характера - ключевой фактор риска атеросклероза и его осложнений. Разработка современных методов исследования метаболома, таких как хромато-массспектрометрия, позволяет существенно расширить представления об особенностях липидного обмена в различных клинических ситуациях.

Обнаружено, что значимую роль здесь могут играть сфигмолипиды (такие как сфингомиелины, церамиды, сфингозин, сфинганин сфингозин-1-фосффат (С1Ф) и т. д.) [1]. Изменение соотношения различных сфинголипидов выявляют при некоторых метаболических, генетических и аутоиммунных заболеваниях (болезни Фабри, НиманнаПика, Гоше и др., некоторых видах эпилепсии, мигрени, болезни Альцгеймера).

Идет активное изучение особенностей липидома при сердечно-сосудистых заболеваниях. Показано прогностическое значение некоторых липидных фракций, преимущественно церамидов, при остром коронарном синдроме. В качестве возможных маркеров риска рассматривают соотношения церамидов С 16 : 0, С 20 : 0, C 24: 1 и их отношения к C $24: 0$.

Прогностическую значимость церамидов оценивали в проспективных исследованиях. Уровень церамидов определяли у больных с острым коронарным синдромом [2]. Было обнаружено, что уровень сфингомиелинов, сфингозина, сфингозин-1-фосфата и церамида может существенно отличаться у больных с острыми и хроническими формами ИБС [3].

В то же время особенности липидома у больных с наследственными дислипидемиями не исследованы. Нет пока и убедительных данных о динамике уровня сфинголипидов и церамидов на фоне липидснижающей терапии, есть лишь единичные случаи сравнения уровня сфинголипидов у пациентов без терапии и на фоне липидснижающей терапии [4, 5].

Целью настоящего исследования было изучить особенности сфинголипидов у пациентов, имеющих различную клиническую вероятность семейной гиперлипидемии.

\section{ПАЦИЕНТЫ И МЕТОДЫ}

Исследование проводили на базе Городской клинической больницы № 51 г. Москвы в марте-октябре 2019 г. В исследовании приняли участие 35 пациентов. В обследованной группе было 15 мужчин (42,9\%) и 20 женщин (57,1\%), средний возраст пациентов составил 49,8 \pm 9,96 лет. Критерии включения: ранние проявления атеросклероза ишемической болезни сердца, симптомного периферического атеросклероза или цереброваскулярной болезни с дебютом заболевания в возрасте до 55 лет у мужчин и до 60 лет у женщин и/или дислипидемиями (уровень ЛНП > 4,9 ммоль/л). Критерии исключения: острый инфаркт миокарда, острый инсульт, сахарный диабет, вторичные дислипидемии. В исследование не включали пациентов, получавших на момент обследования липидснижающую терапию.

У 16 пациентов на момент включения в исследование была артериальная гипертензия (45,7\%), у 10 (28,6\%) - ИБС, у одного пациента (2,9\%) - симптомный периферический атеросклероз. Девятнадцать пациентов (54,3\%) имели отягощенный по сердечно-сосудистым заболеваниям семейный анамнез. Девять пациентов (25,7\%) курили ранее, но прекратили курение до включения в исследование,
8 пациентов курили на момент включения в исследование (22,9\%).

Вероятность наличия семейной гиперхолестеринемии (СГХС) рассчитывали по шкале сети голландских липидных клиник. У 10 пациентов вероятность СГХС оценивали как низкую (1-2 балла), у 22 пациентов диагноз расценивали как вероятную СГХС (3-5 баллов). У 3 пациентов была возможная или определенная СГХС (2 пациента - 6 баллов, один пациент - 9 баллов).

Взятие крови для биохимического и массспектрометрического анализа осуществляли в день включения пациентов в исследование (утром натощак, после 12-часового голодания). Взятие крови проводили из кубитальной вены в стерильные пробирки типа «вакутейнер». Сыворотку получали путем центрифугирования крови на скорости 3000 об./мин в течение 15 мин. Определяли параметры со следующими референсными значениями: общий холестерин (ОХС, 2,0-5,2 ммоль/л), холестерин липопротеинов низкой плотности (ХС ЛНП, до 3,3 ммоль/л), липопротеинов высокой плотности (ХС ЛВП, 0,91-1,56 ммоль/л), триглицеридов сыворотки крови (ТГ, 0,50-1,70 ммоль/л). Для определения параметров сыворотки использовали биохимический анализатор CLIMA MC-15 (RAL; Испания).

Липиды выделяли из плазмы по методу БлайяДайера [6]. Масс-спектрометрическое детектирование молекулярных видов сфингомиелинов, церамидов и сфингоидных оснований (сфингозина и сфинганина), а также галактозилцерамидов проводили с помощью прибора TSQ Endura (Thermo Fisher Scientific; Германия) в режиме мониторинга множественных реакций (MMP) при давлении в ячейке соударений 1,5 мТорр. Разрешение на Q1 и Q3 составляло 1,2 Да.

Для церамидов фррагментацию исходных протонированных и дегидратированных молекул проводили при энергии 25 эВ до иона с отношением массы к заряду (m/z) 264,4 Да, время удержания составляло 25 мс.

Для сфингомиелинов фрагментацию исходных протонированных молекул проводили при энергии 25 эВ до иона с m/z 184,1 Да, время удержания составляло 25 мс.

Для сфингозина и его дейтерированного стандарта (d7, Avanti; США) фррагментацию протонированных молекул проводили при энергии 12,5 эВ до ионов с m/z 264,4 и 259,3 Да соответственно, время удержания составляло 25 мс. Для сфинганина фррагментацию исходной протонированной молекулы проводили при энергии 12,5 эВ до иона с m/z 266,4 Да, время удержания составляло 50 мс.

Для галактозилцеромида d18 : 1/18: 0: ион $[\mathrm{M}+\mathrm{H}]^{+} \mathrm{C}$ массой 728,5 Да.

Использовали следующие параметры источника ионизации: температура нагревателя $300{ }^{\circ} \mathrm{C}$, температура капилляра $340^{\circ} \mathrm{C}$, поток газа завесы - 45 п.е. (приборные единицы), поток вспомогательного газа - 13 п.е., поток продувочного газа -1 п.е.

В качестве стандартов использовали сфингозин d7, сфинганин, сфингомиелин d18:1/16: 0, сфингомиелин d18 : 1/18 : 0, церамид d18 : 1/16 : 0, церамид d18 : 1/18: 1, церамид d18:1/18:0, церамид d18:1/24:1, церамид d18 : 1/24 : 0, галактозилцерамид d18 : 1/18 : 0 (Avanti; США).

\section{Хроматографическое разделение}

Хроматографическое разделение проводили с использованием системы Ultimate 3000 (Thermo Fisher Scientific; Германия) на колонке Eclipse Plus C8 3.0 × 150 мм 
(Agilent; США), размер частиц 3,5 мкм. Температура составляла $50{ }^{\circ} \mathrm{C}$, поток - 400 мкл/мин.

При определении сфингозина, церамидов и сфингомиелина использовали следующие составы мобильных фаз: фаза А - вода + 0,1\% (по объему) муравьиной кислоты, фаза Б - метанол + 0,1\% (по объему) муравьиной кислоты (0,7 мин 55\% фазы Б, 100\% фазы Б к 6, 7-й мин, 100\% фазы Б до 12-й мин, 55\% фразы Б от 13-й до 17-й мин, 55\% фазы Б к 13-й мин).

При определении сфинганина использовали следующие составы мобильных фаз: фраза А - вода + 0,1\% (по объему) муравьиной кислоты, фраза Б - 50\% метанол + 50\% ацетонитрил + 0,1\% (по объему) муравьиной кислоты (1,5 мин 20\% фазы Б, 100\% фазы Б к 3, 2-й мин, 100\% фазы Б до 6, 7-й мин, 20\% фазы Б к 7, 7 мин, 20\% фазы Б до 10-й мин)

\section{Обработка данных}

Относительное содержание церамидов оценивали по внешней калибровке (метод стандарта). В качестве калибранта использовали смесь церамидов Ceramide Porcine Brain 860052P (Avanti; США) с содержанием церамида d18 : 1/18 : 0 50\% и d18 : 1/24 : 1 20\%. Вычисления проводили по сумме площадей пиков ММР-переходов $\mathrm{MH}^{+\cdot} \rightarrow \mathrm{m} / \mathrm{z} 264,4$ Да и $\left(\mathrm{MH}-\mathrm{H}_{2} \mathrm{O}\right)^{++} \rightarrow \mathrm{m} / \mathrm{z}$ 264,4 Да.

Калибрантом для сфингомиелинов были смесь Sphingomielin Porcine Brain 860062P (Avanti; CШA) и сфингомиелины d18 : 1/16 : 0, d18 : 1/18 : 0 (Avanti; США). Вычисление проводили по площадям пиков MRMпереходов $\mathrm{MH}^{++} \rightarrow \mathrm{m} / \mathrm{z}$ 184,1 Да.

Содержание сфингозина d18 : 1 определяли по внутренней калибровке (метод внутреннего стандарта, стандарт D-erythro-sphingosine d7, Sigma; CША) по площадям ММР-переходов $\left(\mathrm{m} / \mathrm{z} 300^{+*} \rightarrow \mathrm{m} / \mathrm{z} 264,4\right.$ Да для недейтерированного и $\mathrm{m} / \mathrm{z} 307^{+*} \rightarrow \mathrm{m} / \mathrm{z}$ 259,3 Да для дейтерированного сфингозина).

Содержание сфинганина d18:0 определяли по внешней калибровке (стандарт - DL-erythro-dihidrosphingosine, Sigma; США) по площадям ММР-переходов m/z 302+ m/z 266 Да.

\section{Статистическая обработка результатов}

Статистическую обработку результатов проводили с помощью пакета программ SPSS, версия 23.0 (IBM; США). Количественные переменные представлены в виде

Таблица 1. Уровень липидов и сфинголипидов у пациентов с различной клинической вероятностью семейной гиперлипидемии

\begin{tabular}{|c|c|c|c|c|}
\hline \multirow{2}{*}{ Параметры } & $\begin{array}{l}\text { Низкая вероятность СГХС } \\
(n=10)\end{array}$ & $\begin{array}{c}\text { Возможная СГХС } \\
(n=22)\end{array}$ & $\begin{array}{c}\text { Вероятная/определенная } \\
\text { СГХС }(n=3)\end{array}$ & $p$ \\
\hline & 1 & 2 & 3 & \\
\hline ОХС, ммоль/л & $6,79 \pm 0,627$ & $8,04 \pm 1,746$ & $12,00 \pm 5,344$ & 0,006 \\
\hline ЛНП, ммоль/л & $4,32 \pm 0,45435$ & $5,40 \pm 0,973$ & $7,24 \pm 1,447$ & 0,001 \\
\hline лВП, ммоль/л & $1,52 \pm 0,431$ & $1,45 \pm 0,457$ & $1,15 \pm 0,578$ & 0,713 \\
\hline ТГ, ммоль/л & $1,81 \pm 1,123$ & $2,46 \pm 3,245$ & $5,80 \pm 6,141$ & 0,240 \\
\hline Сфингозин, нг/мл & $50,14 \pm 62,409$ & $83,59 \pm 70,774$ & $144,36 \pm 107,863$ & $\begin{array}{c}0,051 \\
{ }^{*} 0,010 \text { (группы } 1 \text { и 3) }\end{array}$ \\
\hline Сфинганин, нг/мл & $0,752 \pm 0,3713$ & $0,895 \pm 0,5841$ & $1,663 \pm 1,4619$ & 0,142 \\
\hline Галактозилцерамид, нг/мл & $55,48 \pm 29,867$ & $66,60 \pm 43,291$ & $76,95 \pm 25,626$ & 0,473 \\
\hline \multicolumn{5}{|c|}{ Сфингомиелины } \\
\hline SM $18: 1 / 16: 0$, мкг/мл & $18997,6 \pm 13203,93$ & $15407,2 \pm 7769,07$ & $9557,6 \pm 2435,11$ & 0,274 \\
\hline SM $18: 1 / 16: 1$, мкг/мл & $1893,9 \pm 714,16$ & $1861,1 \pm 1642,95$ & $2208,3 \pm 1071,19$ & 0,432 \\
\hline SM $18: 1 / 18: 0$, мкг/мл & $3646,2 \pm 2447,91$ & $3322,6 \pm 1981,05$ & $2392,6 \pm 1758,81$ & 0,629 \\
\hline SM $18: 1 / 18: 1$, мкг/мл & $6138,8 \pm 4915,11$ & $5605,4 \pm 2747,14$ & $7240,6 \pm 3716,52$ & 0,806 \\
\hline SM $18: 1 / 20: 0$, мкг/мл & $19573,6 \pm 9198,49$ & $22693,9 \pm 15985,31$ & $24874,3 \pm 6191,24$ & 0,525 \\
\hline SM $18: 1 / 20: 1$, мкг/мл & $55331,1 \pm 34643,17$ & $55612,7 \pm 32720,49$ & $45554,0 \pm 17549,55$ & 0,924 \\
\hline SM $18: 1 / 22: 0$, мкг/мл & $6484,3 \pm 3692,833$ & $7141,1 \pm 2842,95$ & $10927,6 \pm 4151,37$ & 0,028 \\
\hline SM $18: 1 / 22: 1$, мкг/мл & $407,4 \pm 191,59$ & $416,9 \pm 211,78$ & $478,6 \pm 143,01$ & 0,721 \\
\hline SM $18: 1 / 24: 0$, мкг/мл & $1759,7 \pm 1613,16$ & $2155,4 \pm 1063,40$ & $1728,0 \pm 337,634$ & 0,328 \\
\hline SM $18: 1 / 24: 1$, мкг/мл & $6095,1 \pm 3364,35$ & $4835,2 \pm 2611,45$ & $4711,3 \pm 1018,43$ & 0,569 \\
\hline \multicolumn{5}{|c|}{ Церамиды } \\
\hline С $18: 0$, мкг/мл & $3,70 \pm 8,820$ & $6,04 \pm 9,740$ & $0,018 \pm 0,186$ & 0,513 \\
\hline С $20: 0$, мкг/мл & $224,70 \pm 655,577$ & $240,60 \pm 431,668$ & $367,67 \pm 144,417$ & 0,075 \\
\hline С $20: 1$, мкг/мл & $85,10 \pm 124,969$ & $98,00 \pm 229,133$ & $698,67 \pm 1138,155$ & 0,019 \\
\hline С $22: 0$, мкг/мл & $149,60 \pm 347,728$ & $75,96 \pm 71,642$ & $221,33 \pm 170,365$ & 0,100 \\
\hline С $22: 1$, мкг/мл & $77,00 \pm 82,254$ & $60,80 \pm 111,859$ & $714,67 \pm 1118,787$ & 0,003 \\
\hline С $24: 0$, мкг/мл & $587,80 \pm 200,069$ & $737,96 \pm 354,259$ & $782,00 \pm 357,669$ & 0,598 \\
\hline С $24: 1$, мкг/мл & $206,20 \pm 77,150$ & $313,08 \pm 254,952$ & $465,67 \pm 457,362$ & 0,546 \\
\hline С $18: 0 / C 24: 0$, мкг/мл & $0,0043 \pm 0,00938$ & $0,0079 \pm 0,01275$ & $0,0000 \pm 0,00000$ & 0,963 \\
\hline С $24: 1 /$ C $24: 0$, мкг/мл & $0,3678 \pm 0,13805$ & $0,4600 \pm 0,35776$ & $0,5124 \pm 0,29631$ & 0,675 \\
\hline
\end{tabular}

Примечание: сравнение по критерию Краскела-Уоллиса. 
среднего с учетом стандартного отклонения. Для всех переменных была выполнена проверка на соответствие нормальному распределению с использованием теста Шапиро-Уилка. Распределение всех количественных переменных отличалось от нормального. Достоверность различий оценивали для двух независимых выборок по критерию Манна-Уитни, для трех и более выборок - по критерию Краскела-Уоллиса. Значимость корреляций определяли по критерию Спирмена. Для всех видов анализа достоверными считали различия при $p<0,05$.

\section{РЕЗУЛЬТАТЫ ИССЛЕДОВАНИЯ}

Сравнение уровня липидов крови и сфинголипидов было проведено в группах пациентов с различной клинической вероятностью семейной гиперлипидемии (табл. 1).

У пациентов с СГХС наблюдали более высокий уровень ОХС и ЛНП. Кроме того, у пациентов с СГХС отмечали тенденцию к повышению уровню сфингозина по сравнению с группой пациентов с низкой вероятностью
СГХС $(p<0,05)$. У больныХ с СГХС отмечали увеличение доли длинноцепочечного сфингомиелина SM 18 : 1/22 : 0, а также выявляли существенное повышение уровня церамидов с длинной углеродной цепью, С $20: 1$ и С 22 : 1. Достоверных различий в соотношениях С 18 : 0/С 24 : 0 и С 24 : 1/С 24 : 0 обнаружено не было.

Мы проанализировали связь между уровнем различных липидов и сфинголипидов и наличием у пациентов отягощенного семейного анамнеза (табл. 2). Пациенты с отягощенным семейным анамнезом имели более высокий уровень сфингозина и достоверно более высокий уровень церамидов С 20 : 0, С $20: 1$, С 22 : 0.

Была выявлена прямая корреляция уровня ЛПН и сфингозина (рис. 1). Кроме того, удалось выявить обратные корреляции уровня ЛВП, сфинганина (рис. 2) и галактозилцерамида ( $r=-0,56 ; p=0,001)$. Корреляционный анализ уровня фракций сфингомиелинов и церамидов с «классическими» липидными фракциями представлен в табл. 3. Обращает на себя внимание прямая корреляция уровня церамидов С 24 : 0 и С 24 : 1 с уровнем ОХС и ЛНП.

Таблица 2. Уровень липидов и сфинголипидов у пациентов с различной клинической вероятностью семейной гиперлипидемии

\begin{tabular}{|c|c|c|c|}
\hline Параметры & Семейный анамнез не отягощен $(n=16)$ & Семейный анамнез отягощен $(n=19)$ & $p$ \\
\hline ОХС, ммоль/л & $8,11 \pm 1,142$ & $7,35 \pm 1,881$ & 0,026 \\
\hline ЛНП, ммоль/л & $5,49 \pm 1,063$ & $4,75 \pm 0,820$ & 0,039 \\
\hline лВП, ммоль/л & $1,63 \pm 0,352$ & $1,32 \pm 0,479$ & 0,034 \\
\hline ТГ, ммоль/л & $1,91 \pm 1,119$ & $2,57 \pm 3,712$ & 0,845 \\
\hline Сфингозин, нг/мл & $65,31 \pm 55,298$ & $82,37 \pm 84,841$ & 0,021 \\
\hline Сфинганин, нг/мл & $0,25 \pm 0,447$ & $0,47 \pm 0,612$ & 0,062 \\
\hline Галактозилцерамид, нг/мл & $59,38 \pm 46,989$ & $67,00 \pm 33,579$ & 0,123 \\
\hline \multicolumn{4}{|c|}{ Сфингомиелины } \\
\hline SM $18: 1 / 16: 0$, мкг/мл & $15812,5 \pm 8874,74$ & $16142,37 \pm 10210,772$ & 0,678 \\
\hline SM $18: 1 / 16: 1$, мкг/мл & $1703,38 \pm 1153,149$ & $2079,74 \pm 1637,244$ & 0,635 \\
\hline SM $18: 1 / 18: 0$, мкг/мл & $3446,00 \pm 2012,195$ & $3115,37 \pm 1651,906$ & 0,942 \\
\hline SM $18: 1 / 18: 1$, мкг/мл & $6066,06 \pm 4210,684$ & $5388,68 \pm 2755,342$ & 0,862 \\
\hline SM $18: 1 / 20: 0$, мкг/мл & $21605,00 \pm 6986,063$ & $22197,89 \pm 18558,786$ & 0,756 \\
\hline SM $18: 1 / 20: 1$, мкг/мл & $57836,31 \pm 37448,414$ & $51584,74 \pm 29461,884$ & 0,684 \\
\hline SM $18: 1 / 22: 0$, мкг/мл & $8366,13 \pm 3752,568$ & $8090,74 \pm 2977,416$ & 0,862 \\
\hline SM $18: 1 / 22: 1$, мкг/мл & $387,56 \pm 224,592$ & $441,26 \pm 183,190$ & 0,672 \\
\hline SM $18: 1 / 24: 0$, мкг/мл & $1809,31 \pm 983,979$ & $2218,1 \pm 1409,971$ & 0,584 \\
\hline SM $18: 1 / 24: 1$, Мкг/Мл & $5398,19 \pm 2713,511$ & $5094,32 \pm 2995,497$ & 0,682 \\
\hline \multicolumn{4}{|c|}{ Церамиды } \\
\hline С $18: 0$, мкг/мл & $6,31 \pm 10,163$ & $4,58 \pm 8,946$ & 0,213 \\
\hline С $20: 0$, мкг/мл & $78,56 \pm 150,510$ & $391,21 \pm 629,556$ & 0,021 \\
\hline С $20: 1$, мкг/мл & $57,38 \pm 108,836$ & $121,32 \pm 257,882$ & 0,010 \\
\hline С $22: 0$, мкг/мл & $60,19 \pm 64,744$ & $130,21 \pm 252,256$ & 0,040 \\
\hline С $22: 1$, мкг/мл & $47,75 \pm 52,003$ & $77,16 \pm 133,153$ & 0,252 \\
\hline С 24 : 0, мкг/мл & $726,69 \pm 334,931$ & $622,16 \pm 255,175$ & 0,572 \\
\hline С $24: 1$, мкг/мл & $324,25 \pm 264,550$ & $247,05 \pm 181,903$ & 0,457 \\
\hline С $18: 0 /$ С $24: 0$, мкг/мл & $0,0072 \pm 0,01166$ & $0,0067 \pm 0,01235$ & 0,323 \\
\hline С $24: 1 / \mathrm{C} 24: 0$, мкг/мл & $0,4730 \pm 0,37832$ & $0,4078 \pm 0,24104$ & 0,872 \\
\hline
\end{tabular}

Примечание: сравнение по критерию Манна-Уитни. 


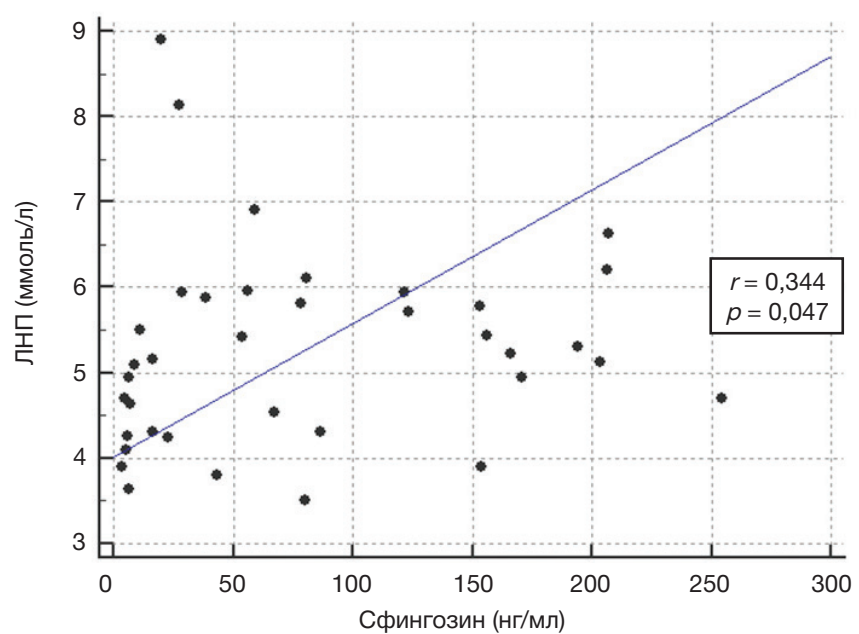

Рис. 1. Корреляция уровней сфингозина и ЛПН

Для церамида С 20 : 0 была выявлена прямая корреляция с уровнем ЛВП и триглицеридов и обратная - с уровнем ЛНП. Для церамида С 22 : 0 была обнаружена обратная корреляция с уровнем ЛВП.

Нами были проанализированы корреляции между уровнем классических липидов и сфинголипидов у пациентов с отягощенным и неотягощенным семейными анамнезами. Обращает на себя внимание тот факт, что прямая корреляция между уровнем ХС ЛНП и сфингозина, выявленная в целом по группе, имела большую силу у пациентов с отягощенным семейным анамнезом ( $r=0,536$; $p=0,022)$. У пациентов с неотягощенным семейным анамнезом корреляция между уровнем холестерина ЛНП и сфингозина была обратной $(r=-0,351 ; p=0,048)$ (рис. 3).

\section{ОБСУЖДДЕНИЕ РЕЗУЛЬТАТОВ}

Исследований особенностей профиля сфингомиелинов и церамидов у пациентов с семейной гиперлипидемией немного. На животной модели семейной гиперлипидемии, вызванной мутациями гена рецептора липопротеинов низкой плотности, было показано достоверное увеличение общего ссрингомиелина и церамида С 18 : 0 при гомозиготном носительстве мутации [7]. В настоящем исследовании мы отмечали только увеличение фракции SM $18: 1 / 22: 0$ и церамида С $20: 1$.

Показана связь уровня церамидов с другими факторами риска развития ИБС - избыточной массой тела и формированием инсулинорезистентности. Считается, что некоторые фракции церамидов могут стимулировать синтез провоспалительных цитокинов (например, фактора некроза опухоли) при повышенном потреблении сатурированных жиров с пищей [8]. При снижении веса после проведения бариатрических хирургических вмешательств снижение уровня атерогенных сфиногомиелинов и церамидов наблюдается раньше и в значительно большей степени, чем происходит снижение веса, что коррелирует со снижением сердечнососудистых рисков [9].

Установлено, что в окисленных ЛНП существенно выше оказывается содержание общих сфинголипидов и церамидов, что может служить подтверждением роли сфинголипидов в дестабилизации атеросклеротической бляшки и формировании обострения ИБС и других заболеваний [10]. Сфингозин вызывает агрегацию $\mathrm{Cu}^{2+}$ перекисных везикул и ускоряет процессы перекисного

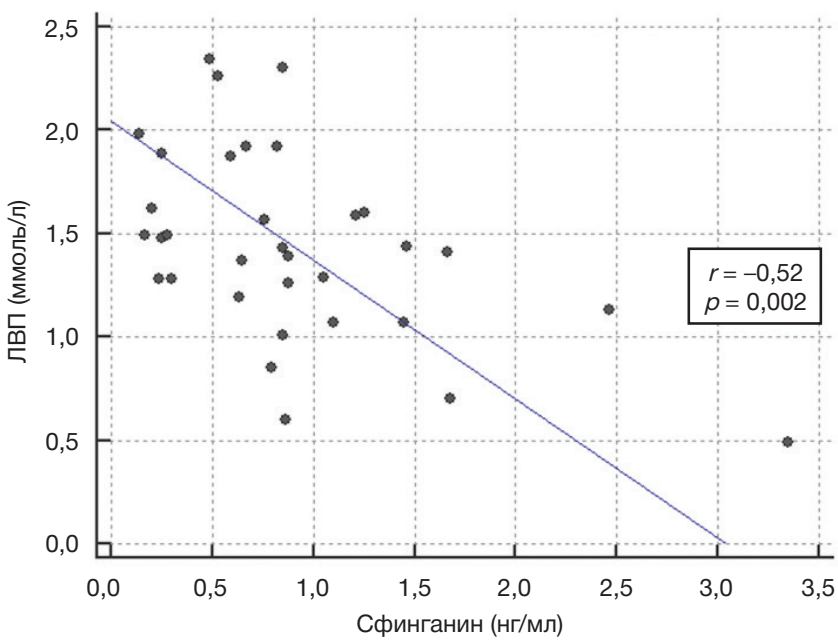

Рис. 2. Корреляция уровней ЛВП и сфинганина крови

окисления ЛНП, делая их более атерогенными Катализаторами этого процесса могут служить длинноцепочечные церамиды. Церамиды с длиной цепи C 6, C 8, С 10 такой активностью не обладают. Сфинганин, напротив, блокирует процессы перекисного окисления [11]. В нашем исследовании у пациентов с определенной семейной дислипидемией отмечали существенное повышение уровня сфингозина. Уровень сфинганина у пациентов с низкой и высокой вероятностью семейной гиперлипидемии достоверно не отличался.

Полиморфизм гена ApoE (2/3/4) ассоциирован с увеличением патогенных фракций церамидов, что связывают с увеличением риска ИБС у молодых пациентов [12].

В патогенезе каротидного атеросклероза у больных с ВИЧ-инфекцией было показано значение уровня церамидов C 16 : 0, C 22 : 0, C 24 : 0, С 24 : 1. Для длинноцепочечных церамидов C 22 и C 24 была установлена корреляция С уровнем ОХС и ЛНП [13]. Положительная корреляция сфингомиелинов SM d16 : 0/28: 5, SM d18 : 1/24: 1 и SM d $18: 1 / 16: 0$ с уровнем ОХС и XС ЛНП была обнаружена при исследовании животной модели дислипидемии (АроЕ-десицитные мыши). Уровень указанных фракций у животных с гиперлипидемией был повышен. Такие сфринголипиды считаются проатерогенными [14]. Есть данные о том, что окислительный стресс и липотоксичность ассоциированы именно с увеличением уровня длинноцепочечных церамидов, что, например, становится явным в условиях инсулинорезистентности [15]. В нашем исследовании уровень сфингомиелина SM $18: 1 / 22: 0$ был повышен у пациентов с вероятной/ определенной гиперлипидемией. Были выявлены прямые корреляции уровня холестерина крови и церамидов C $24: 0$ и C $24: 1$.

Настоящее исследование имеет ряд ограничений, таких как одноцентровой характер исследования, малый объем выборки, отсутствие данных крупных наблюдательных исследований о наличии эпидемиологической связи между выявленными изменениями компонентов липидома и сердечно-сосудистыми событиями (инфаркты, инсульты, сердечно-сосудистая смерть).

\section{ВЫВОДЫ}

Пациенты с определенной/вероятной СГХС имеют не только высокий уровень ОХС и ХС ЛНП, но и проатерогенного сфингозина, сфингомиелина SM $18: 1 / 22: 0$, церамидов с 
Таблица 3. Корреляции уровней липидов крови и сфингомиелинов и церамидов

\begin{tabular}{|c|c|c|c|c|c|}
\hline & & ОХС, ммоль/л & ТГ, ммоль/л & ХС ЛНП, ммоль/л & ХС ЛВП, ммоль/л \\
\hline \multirow[b]{2}{*}{ SM $18: 1 / 16: 0$, мкг/мл } & $r$ & 0,178 & $-0,104$ & 0,084 & 0,162 \\
\hline & $p$ & 0,307 & 0,564 & 0,636 & 0,391 \\
\hline \multirow{2}{*}{ SM $18: 1 / 16: 1$, Мкг/Мл } & $r$ & 0,260 & $-0,171$ & 0,093 & 0,045 \\
\hline & $p$ & 0,132 & 0,341 & 0,602 & 0,813 \\
\hline \multirow{2}{*}{ SM $18: 1 / 18: 0$, мкг/мл } & $r$ & 0,257 & $-0,140$ & 0,278 & 0,236 \\
\hline & $p$ & 0,135 & 0,439 & 0,111 & 0,210 \\
\hline \multirow{2}{*}{ SM $18: 1 / 18: 1$, мкг/мЛ } & $r$ & $-0,139$ & $-0,095$ & $-0,202$ & 0,077 \\
\hline & $p$ & 0,426 & 0,597 & 0,251 & 0,686 \\
\hline \multirow{2}{*}{ SM $18: 1 / 20: 0$, мкг/мЛ } & $r$ & $0,363^{*}$ & $-0,015$ & 0,184 & $-0,110$ \\
\hline & $p$ & 0,032 & 0,934 & 0,297 & 0,561 \\
\hline \multirow[b]{2}{*}{ SM $18: 1 / 20: 1$, мкг/мл } & $r$ & $-0,101$ & 0,111 & $-0,098$ & 0,334 \\
\hline & $p$ & 0,562 & 0,540 & 0,581 & 0,072 \\
\hline \multirow[b]{2}{*}{ SM $18: 1 / 22: 0$, мкг/мл } & $r$ & $-0,017$ & $-0,313$ & $-0,155$ & 0,165 \\
\hline & $p$ & 0,924 & 0,076 & 0,383 & 0,382 \\
\hline \multirow{2}{*}{ SM $18: 1 / 22: 1$, мкг/Мл } & $r$ & 0,082 & 0,146 & 0,125 & $-0,187$ \\
\hline & $p$ & 0,642 & 0,419 & 0,481 & 0,321 \\
\hline \multirow[b]{2}{*}{ SM $18: 1 / 24: 0$, мкг/мл } & $r$ & 0,048 & $-0,183$ & 0,100 & $-0,254$ \\
\hline & $p$ & 0,782 & 0,307 & 0,572 & 0,175 \\
\hline \multirow[b]{2}{*}{ SM $18: 1 / 24: 1$ мкг/мл } & $r$ & 0,217 & $-0,297$ & 0,148 & 0,046 \\
\hline & $p$ & 0,210 & 0,094 & 0,403 & 0,809 \\
\hline \multirow[b]{2}{*}{ С $18: 0$, мкг/мл } & $r$ & 0,104 & $-0,041$ & 0,105 & $-0,104$ \\
\hline & $p$ & 0,552 & 0,820 & 0,556 & 0,584 \\
\hline \multirow[b]{2}{*}{ С $20: 0$, мкг/мл } & $r$ & 0,055 & 0,141 & $-0,003$ & $-0,420^{*}$ \\
\hline & $p$ & 0,752 & 0,433 & 0,987 & 0,021 \\
\hline \multirow[b]{2}{*}{ С $20: 1$, мкг/мл } & $r$ & $-0,177$ & $0,447^{\star \star}$ & $-0,425^{\star}$ & $0,525^{\star \star}$ \\
\hline & $p$ & 0,310 & 0,009 & 0,012 & 0,003 \\
\hline \multirow[b]{2}{*}{ С $22: 0$, мкг/мл } & $r$ & 0,015 & 0,342 & 0,049 & $-0,429^{\star}$ \\
\hline & $p$ & 0,932 & 0,052 & 0,783 & 0,018 \\
\hline \multirow[b]{2}{*}{ С $22: 1$, мкг/мл } & $r$ & 0,070 & 0,051 & $-0,094$ & $-0,168$ \\
\hline & $p$ & 0,689 & 0,776 & 0,598 & 0,374 \\
\hline \multirow[b]{2}{*}{ С $24: 0$, мкг/мл } & $r$ & $0,475^{\star \star}$ & 0,100 & 0,334 & 0,008 \\
\hline & $p$ & 0,004 & 0,579 & 0,054 & 0,965 \\
\hline \multirow{2}{*}{ С $24: 1$, мкг/мл } & $r$ & $0,558^{* *}$ & 0,005 & $0,471^{\star *}$ & 0,296 \\
\hline & $p$ & 0,000 & 0,976 & 0,005 & 0,112 \\
\hline
\end{tabular}

Примечание: $r$ - коэффрициент корреляции Спирмена; * $-p<0,005 ;{ }^{* *}-p<0,001$. 


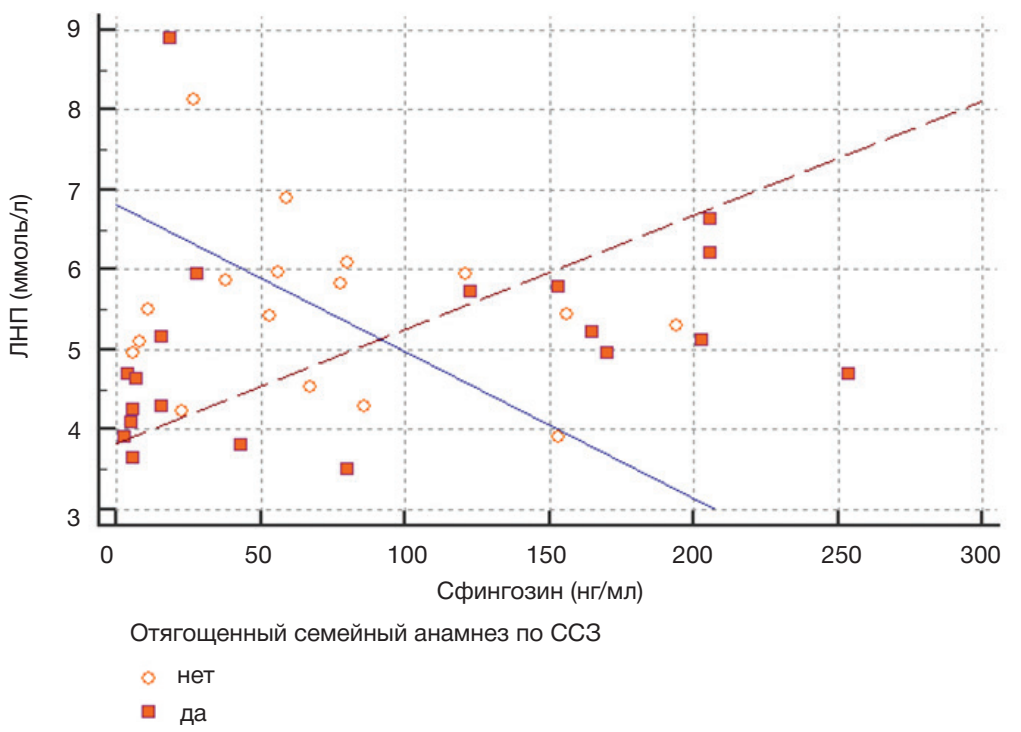

Рис. 3. Корреляция уровней ЛНП и сфингозина крови

длинной углеродной цепью (С 20 : 1 и С 22 : 1). Выявленные нами особенности липидома требуют уточнения их клинической значимости. Наличие изменений липидома может объяснять механизм повышения риска развития и раннего дебюта атеросклероза в этой группе пациентов.
О значении сфингозина как дополнительного фактора риска, ассоциированного с семейным характером заболевания, свидетельствует то, что прямая корреляция между уровнем сфингозина и ЛНП была выявлена только у пациентов с отягощенным семейным анамнезом.

\section{Литература}

1. Matanes F, Twal WO, Hammad SM. Sphingolipids as biomarkers of disease. Adv Exp Med Biol. 2019; (1159): 109-38. DOI: 10.1007/978-3-030-21162-2 7.

2. Anroedh S, Hilvo M, Akkerhuis KM, Kauhanen D, Koistinen K, Oemrawsingh $\mathrm{R}$, et al. Plasma concentrations of molecular lipid species predict long-term clinical outcome in coronary artery disease patients. J Lipid Res. 2018; 59 (9): 1729-37. DOI: 10.1194/jlr.P081281

3. Sutter I, Klingenberg R, Othman A, Rohrer L, Landmesser U, Heg D, et al. Decreased phosphatidylcholine plasmalogens - a putative novel lipid signature in patients with stable coronary artery disease and acute myocardial infarction. Atherosclerosis. 2016; (246): 130-40. DOI: 10.1016/i.atherosclerosis.2016.01.003.

4. Ng TW, Ooi EM, Watts GF, Chan DC, Meikle PJ, Barrett PH. Association of plasma ceramides and sphingomyelin with VLDL apoB-100 fractional catabolic rate before and after rosuvastatin treatment. J Clin Endocrinol Metab. 2015; 100 (6): 2497-501. DOI: 10.1210/jc.2014-4348. PubMed PMID: 25816050.

5. Tarasov K, Ekroos K, Suoniemi M, Kauhanen D, Sylvänne T, Hurme R, et al. Molecular lipids identify cardiovascular risk and are efficiently lowered by simvastatin and PCSK9 deficiency. J Clin Endocrinol Metab. 2014; 99 (1): E45-52. DOI:10.1210/jc.20132559. PubMed PMID: 24243630; PubMed Central PMCID: PMC3928964.

6. Bligh EG, Dyer WJ. A rapid method of total lipid extraction and purification. Can J Biochem Physiol. 1959; 37 (8): 911-7.

7. Hoogendoorn A, den Hoedt S, Hartman EMJ, Krabbendam-Peters I, Te Lintel Hekkert M, van der Zee L, et al. Variation in coronary atherosclerosis severity related to a distinct LDL (Low-Density Lipoprotein) profile: findings from a familial hypercholesterolemia pig model. Arterioscler Thromb Vasc Biol. 2019; 39 (11): 2338-52. DOI:10.1161/ATVBAHA.119.313246.

8. Sokolowska E, Blachnio-Zabielska A. The role of ceramides in

insulin resistance. Front Endocrinol (Lausanne). 2019; (10): 577. DOl: 10.3389/fendo.2019.00577.

9. Kayser BD, Lhomme M, Dao MC, Ichou F, Bouillot JL, Prifti E, et al. Serum lipidomics reveals early differential effects of gastric bypass compared with banding on phospholipids and sphingolipids independent of differences in weight loss. Int $\mathrm{J}$ Obes (Lond). 2017; 41 (6): 917-25. DOI: 10.1038/ijo.2017.63.

10. Paul A, Lydic TA, Hogan R, Goo YH. Cholesterol acceptors regulate the lipidome of macrophage foam cells. Int $\mathrm{J}$ Mol Sci. 2019; 20 (15): E3784-801. DOI: 10.3390/ijms20153784.

11. Jiménez-Rojo N, Viguera AR, Collado MI, Sims KH, Constance C, Hill KS, et al. Sphingosine induces the aggregation of iminecontaining peroxidized vesicles. Biochim Biophys Acta. 2014; 1838 (8): 2071-7. DOI: 10.1016/j.bbamem.2014.04.028.

12. Karjalainen JP, Mononen N, Hutri-Kähönen N, Lehtimäki M, Hilvo $M(4)$, Kauhanen $D$, et al. New evidence from plasma ceramides links apoE polymorphism to greater risk of coronary artery disease in Finnish adults. J Lipid Res. 2019; 60 (9): 1622-9. DOI: 10.1194/ jlr.M092809.

13. Zhao W, Wang $X$, Deik AA, Hanna DB, Wang T, Haberlen SA, et al. Elevated plasma ceramides are associated with antiretroviral therapy use and progression of carotid artery atherosclerosis in HIV infection. Circulation. 2019; 139 (17): 2003-11. DOI: 0.1161/ CIRCULATIONAHA.118.037487.

14. Chen $Y$, Wen S, Jiang M, Zhu Y, Ding L, Shi H, et al. Atherosclerotic dyslipidemia revealed by plasma lipidomics on ApoE-/- mice fed a high-fat diet. Atherosclerosis. 2017; (262): 78-86. DOI: 10.1016/j. atherosclerosis.2017.05.010.

15. Law BA, Liao X, Moore KS, Southard A, Roddy P, Ji R, et al. Lipotoxic very-long-chain ceramides cause mitochondrial dysfunction, oxidative stress, and cell death in cardiomyocytes. FASEB $\mathrm{J}$ 2018; 32 (3): 1403-16. DOl: 10.1096/fj.201700300R. PubMed PMID: 29127192; PubMed Central PMCID: PMC5892719. 


\section{References}

1. Matanes F, Twal WO, Hammad SM. Sphingolipids as biomarkers of disease. Adv Exp Med Biol. 2019; (1159): 109-38. DOI: 10.1007/978-3-030-21162-2 7

2. Anroedh S, Hilvo M, Akkerhuis KM, Kauhanen D, Koistinen K, Oemrawsingh R, et al. Plasma concentrations of molecular lipid species predict long-term clinical outcome in coronary artery disease patients. J Lipid Res. 2018; 59 (9): 1729-37. DOI: 10.1194/jlr.P081281.

3. Sutter I, Klingenberg R, Othman A, Rohrer L, Landmesser U, Heg D, et al. Decreased phosphatidylcholine plasmalogens - a putative novel lipid signature in patients with stable coronary artery disease and acute myocardial infarction. Atherosclerosis. 2016; (246): 130-40. DOI: 10.1016/j.atherosclerosis.2016.01.003.

4. Ng TW, Ooi EM, Watts GF, Chan DC, Meikle PJ, Barrett PH. Association of plasma ceramides and sphingomyelin with VLDL apoB-100 fractional catabolic rate before and after rosuvastatin treatment. J Clin Endocrinol Metab. 2015; 100 (6): 2497-501. DOI: 10.1210/jc.2014-4348. PubMed PMID: 25816050

5. Tarasov K, Ekroos K, Suoniemi M, Kauhanen D, Sylvänne T, Hurme R, et al. Molecular lipids identify cardiovascular risk and are efficiently lowered by simvastatin and PCSK9 deficiency. J Clin Endocrinol Metab. 2014; 99 (1): E45-52. DOl:10.1210/jc.20132559. PubMed PMID: 24243630; PubMed Central PMCID: PMC3928964.

6. Bligh EG, Dyer WJ. A rapid method of total lipid extraction and purification. Can J Biochem Physiol. 1959; 37 (8): 911-7.

7. Hoogendoorn A, den Hoedt S, Hartman EMJ, Krabbendam-Peters I, Te Lintel Hekkert M, van der Zee L, et al. Variation in coronary atherosclerosis severity related to a distinct LDL (Low-Density Lipoprotein) profile: findings from a familial hypercholesterolemia pig model. Arterioscler Thromb Vasc Biol. 2019; 39 (11): 2338-52. DOI:10.1161/ATVBAHA.119.313246.

8. Sokolowska E, Blachnio-Zabielska A. The role of ceramides in insulin resistance. Front Endocrinol (Lausanne). 2019; (10): 577 DOI: 10.3389/fendo.2019.00577.

9. Kayser BD, Lhomme M, Dao MC, Ichou F, Bouillot JL, Prifti E, et al. Serum lipidomics reveals early differential effects of gastric bypass compared with banding on phospholipids and sphingolipids independent of differences in weight loss. Int J Obes (Lond). 2017; 41 (6): 917-25. DOI: 10.1038/ijo.2017.63.

10. Paul A, Lydic TA, Hogan R, Goo YH. Cholesterol acceptors regulate the lipidome of macrophage foam cells. Int J Mol Sci. 2019; 20 (15): E3784-801. DOI: 10.3390/ijms20153784.

11. Jiménez-Rojo N, Viguera AR, Collado MI, Sims KH, Constance C, Hill KS et al. Sphingosine induces the aggregation of iminecontaining peroxidized vesicles. Biochim Biophys Acta. 2014; 1838 (8): 2071-7. DOI: 10.1016/j.bbamem.2014.04.028.

12. Karjalainen JP, Mononen N, Hutri-Kähönen N, Lehtimäki M, Hilvo $\mathrm{M}(4)$, Kauhanen D, et al. New evidence from plasma ceramides links apoE polymorphism to greater risk of coronary artery disease in Finnish adults. J Lipid Res. 2019; 60 (9): 1622-9. DOl: 10.1194/ jlr.M092809.

13. Zhao W, Wang X, Deik AA, Hanna DB, Wang T, Haberlen SA et al. Elevated plasma ceramides are associated with antiretroviral therapy use and progression of carotid artery atherosclerosis in HIV infection. Circulation. 2019; 139 (17): 2003-11. DOI: 0.1161/ CIRCULATIONAHA.118.037487.

14. Chen $Y$, Wen S, Jiang M, Zhu Y, Ding L, Shi H, et al. Atherosclerotic dyslipidemia revealed by plasma lipidomics on ApoE-/- mice fed a high-fat diet. Atherosclerosis. 2017; (262): 78-86. DOI: 10.1016/j. atherosclerosis.2017.05.010.

15. Law BA, Liao X, Moore KS, Southard A, Roddy P, Ji R, et al. Lipotoxic very-long-chain ceramides cause mitochondrial dysfunction, oxidative stress, and cell death in cardiomyocytes. FASEB J. 2018; 32 (3): 1403-16. DOI: 10.1096/fj.201700300R. PubMed PMID: 29127192; PubMed Central PMCID: PMC5892719. 